\title{
Impact of Media on Social Behavior of Individuals Living in
} Karachi

\author{
Fauzia Imtiaz, Noor Ellahi \& Yawar Hasan Zaidi \\ Dow University of Health Sciences. \\ Princeton University \\ Islamic division, National Bank of Pakistan \\ Corresponding Author: f.imtiaz@duhs.edu.pk
}

\begin{abstract}
Today the world is known as a global village where information is easily accessible. Media plays a vital role in providing information, education and entertainment to the population. Media updates people about the current situations through their news channels which are providing the most up to date news within no time through live evidences and substantiations. Several studies have proved the impact of media directly on the acute stress response to collective trauma. Media coverage of collective traumas may trigger sociological distress in individuals outside the directly affected community. Objective: To determine the effect of media on Social behavior of the population of Karachi Methodology: It's a cross sectional questionnaire based study conducted in different areas of Karachi during, November 2014 to Feb 2015. The questionnaire includes demographic information, the type of media used for obtaining information and the impact of news on the social life of individuals. Results: Among the participants $46.6 \%$ were males and $53.4 \%$ were females. Television is the type of media that was used by most (442) of the population. Results showed that $31.9 \%$ showed no effect on their social life whereas $24.4 \%$ avoided the place/public transport for a few days, $18.6 \%$ didn't go out at night, 17.3 avoided travelling alone and $7.8 \%$ of participants were afraid to go out. Conclusion: Television is the source of information for most people, beside the exaggeration in telecasting the news people continues their work. Their social life is not affected anymore which causes them to become immune to the environment they are facing.
\end{abstract}

\section{Introduction}

Media plays a vital role in providing information, education and entertainment to the population. Today, the world is known as a global village in terms of how information is spread effortlessly and is easily accessible. Media updates people about the current events through their news channels which are providing the most up to date news within no time through live evidences and substantiations. Several studies have proved the impact of media directly on an acute stress response to collective trauma. Media coverage of collective traumas may trigger Psychological distress in individuals outside the directly affected community.

Many Researchers studied different events in the world which showed psychological changes in an individual's behavior. For example, the Boston Marathon bombing of 2013 was the first major terror attack in the U.S. after the $9 / 11$ attacks ${ }^{1}$. Widespread coverage of this event was done by the media and its impact on the directly exposed population was that it caused a collective trauma that had potentially detrimental health effects. Many more examples includes television exposure to the Oklahoma city bombing the 1990 Gulf war, and the 9/11 attacks of World Trade Center have all been associated with widespread diffusion of trauma related symptoms soon after collective trauma (Maarten et.al; 2009).

The Internet was introduced by the United State Government in 1960s, to build robust, fault-tolerant communication through computer network. It is being widely used all over the world now. Since 2007 only in USA the number of users increased by $230 \%$ by the year 2009, this increased globally by $82 \%$ (Diana; 2007). Just like television, the Internet also played an important role in spreading psychological changes. A study was conducted in Sargodha Pakistan on 300 university students; it showed a significant association between the use of the Internet and anxiety both in male and female (Komal et.al; 2013).

The print media is still one of the major sources for health related information. The use of this type of media not only has helped spread news but it also provide health related contents like health diet living style for the prevention of stress related disorders, treatment and prevention from post - traumatic stress disorder (Yourhee Jeong et.al;2013).
It has been concluded by reviewing the studies that the media no matter if it is print or social has its positive impact on social and psychological problems especially the behavior. One can change his healthy life to distress one or vice versa through media.

\section{Methodology}

This is a cross sectional questionnaire based study, conducted on the general population of Karachi during November 2014 to Feb 2015 . The study comprises of a sample population of 634 . The sample size was calculated by open epi.com. The questionnaire consists of a short biography, questions related to information about the type of media used and social behavior of individuals related to news. The data was collected from different areas of Karachi as it is a metropolitan city of Pakistan. Therefore, it comprises of different ethnicities, and so variation of opinion was expected. The data were subjected to SPSS version 16.0 for the calculation of frequency and a chi square test for significance.

\section{Result}

The design of the study was a cross sectional study. The sample size was 634 for which 700 individuals were contacted. Among them 650 were agreed to give the response, so the response rate was $92 \% .634$ fill the correct questionnaire and were included in the study while 16 forms were rejected. Out of 634 participants $46.6 \%$ were males and $53.4 \%$ were females. The distribution of age groups and other demographic variables were shown in table1. Participants were put into three major occupational groups among the students $52.8 \%, 33.6 \%$ were from services (which includes both private and government services) and the unemployed group i.e. $13.6 \%$ (Table 1 ).

Table1. Demographic features of participants.

\begin{tabular}{|l|l|l|}
\hline Characteristics & N & $\%$ \\
\hline Gender & & \\
\hline Male & 291 & 46.6 \\
\hline Female & 334 & 53.4 \\
\hline Age group & & \\
\hline $18-25$ & 411 & 65.7 \\
\hline $26-35$ & 87 & 13.9 \\
\hline $36-45$ & 43 & 6.9 \\
\hline $46-55$ & 41 & 6.6 \\
\hline
\end{tabular}




\begin{tabular}{|l|l|l|}
\hline $56+$ & 43 & 6.9 \\
\hline Occupation & & \\
\hline Student & 330 & 52.8 \\
\hline Unemployed & 85 & 13.6 \\
\hline Services & 210 & 33.6 \\
\hline
\end{tabular}

According to the results, the majority of the participants used TV (442) $(69.7 \%)$ as a source for the daily news, followed by social network (236), newspaper (84) and then radio (24) Fig 1. The total number exceeded the sample size because this was a multiple choice question.

Figure 1: Use of different media by population.

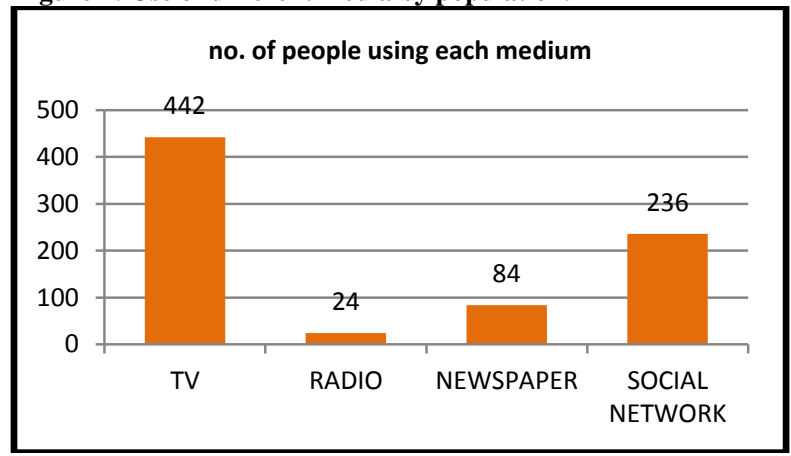

$614(98.24 \%)$ individuals used these sources for about $<5$ hours in a day (table 2).

Table 2: Time related to media exposure to news in a day

\begin{tabular}{|l|l|l|}
\hline Time $(\mathrm{Hrs})$ & $\mathrm{n}$ & $\%$ \\
\hline$<5$ & 614 & 98.24 \\
\hline $6-10$ & 7 & 1.12 \\
\hline $11-15$ & 3 & 0.48 \\
\hline $16-24$ & 1 & 0.16 \\
\hline
\end{tabular}

In our research the participants were also asked for their personal opinion about the role of media in exaggerating the news to which the majority $(66.1 \%)$ responded in affirmation, $25.9 \%$ denied and $8 \%$ said sometimes. We also found that $43.5 \%$ of the participants were of the opinion that the media spreads panic most of the times, $28.8 \%$ said they do it always, $23.2 \%$ said sometimes and $4.5 \%$ thought that media had no role.

The effect on social life was determined by giving our participants five options; $31.9 \%$ had no effect on their social life whereas $24.4 \%$ avoided the place/public transport for a few days, $18.6 \%$ didn't go out at night, 17.3 avoided travelling alone and $7.8 \%$ of participants were afraid to go out (Fig 2).

Fig 2: Social behavior of participants towards news

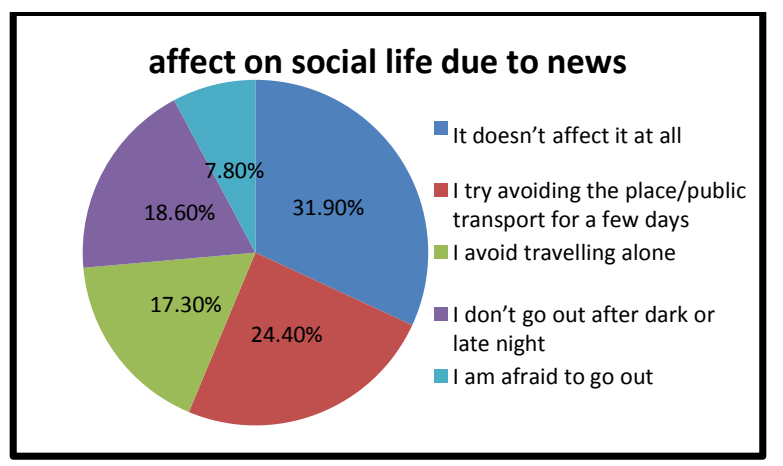

We also asked our participants to evaluate their family's concern when they were not at home. $74.4 \%$ showed concerned about family, $17 \%$ said sometimes and $8.6 \%$ said no (Fig 3).

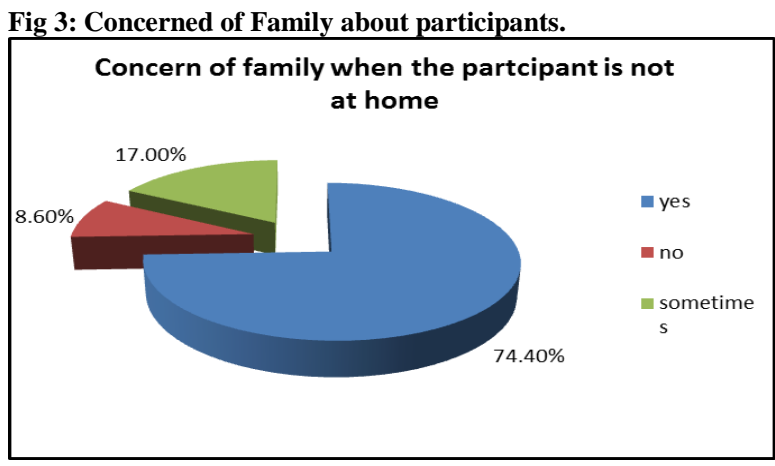

\section{Discussion}

The role of media is becoming increasingly crucial every day and its effects on social life is remarkable. The most important and commonly used media is television which in our study acquired by $69.7 \%$ of the population. In concordance to other studies TV was the most commonly used medium $(68.3 \%)$ as well as in different areas of Karachi (Komal et.al; 2013).

Our study showed that a great number of people were affected by the information provided by media. This same finding was found in the study in Sargodha. Their results also showed that the use of the Internet is more common in male students, as compared to female students. Regression analysis showed a positive and significant relation between internet addiction and anxiety level among University students.

After 9/11, the situation in the USA was also that versed people became more depressed and disturbed and did not even enjoy their work; they were always in a state of anxiety. Researchers especially found out the bad impact of the media after the Boston Marathon bombing. A study from another group in Karachi was conducted during 2010 and it showed that after watching violent news, participants were increasingly stressed ${ }^{3}$. Our study showed that even after hearing about the breaking news, the individuals were still performing their routine work and developed only mild conditions of stress. Although, their family members were very concerned about them going out to work. This can be interpreted as people become immune to news or them becoming braver to face these situations.

The media has now become a part of daily routine for a lot of people in the world. It provides a variety of news, information, entertainment, and events and ways of connecting to peoples from different communities. In the western world, television promotes western concepts of modernity that governments in developing countries find unsuited for their development goals. But they accede to them anyways in order to be accepted as progressive television. This especially becomes a contested site for such tensions in developing countries because of the power of the moving image and televised real life" events to carry loaded convictions of authenticity and veracity for largely illiterate populations. Research has continuously shown that mass media is perceived globally as a very vital instrument for facilitating the development of communities and the nations at large.

So it is recommended for people working in media to work hard for the provision of correct news related to the actual reality. They should also take the responsibility for making the society more enthusiastic and providing a basis for good culture, free of cost health programs, free education and awareness to people. 
A code of conduct should be strictly imposed with the participants of political talk shows in order to avoid sensationalizing news ${ }^{3}$. Repeated telecasting of news of violence should be avoided as it creates propaganda and fear among people and results in selfishness among people.

\section{Conclusion}

The study concludes that media has a significantly great impact on an individual's behavior. Media also exaggerates the news and creates panic-ridden conditions in the population. Whether the media is in a print, audio, or visual form, it carries the same impact.

\section{Conflict of Interest}

No conflict of interest between authors

\section{Acknowledgment}

I acknowledge members of my research group B1final year MBBS DMC for collecting the data.

\section{References}

- Arat, Z. F. (2003). Democracy and Human Rights in Developing Countries, Iuniverse Inc.

- Diana, (2007). Social media up to 230\% since 2007.Information week software report.Retrieved from https/www.informationweek.com.

- E. Alison Holman, Dana Rose Garfin, and Roxane Cohen Silver (2014) Media's role in broadcasting acute stress following the Boston Marathon bombings Proc Natl Acad Sci U S A. Jan 7, 111(1): 93-98.

- Komal Madad Ali Daredia, Nosheen Zehra, Shahida Rasheed (2013) Psychological Effects of Viewing News Channels Among Adult Population of Karachi, Pakistan Pakistan Journal of Medicine and Dentistry, Vol. 2 (01): 24-32

- Maarten H.W. Selfhout, Susan J.T. Branje , M. Delsing ,Tom F.M. ter Bogt, Wim H.J. Meeus (2009) Different types of Internet use, depression, and social anxiety:The role of perceived friendship quality Journal of Adolescence 32 819833.

- Manyozo, L. (2007). Communication for development: An historical overview. UNESCO / IAMCR Conference Report, Paris.

- Musarrat Azher, Rashid Behram Khan Muhammad Salim Muhammad Bilal Altaf Hussain Mehvish Haseeb (2014). The Relationship between Internet Addiction and Anxiety among students ofUniversity of Sargodha. International Journal of Humanities and Social Science: Vol. 4 No. 1; January 2014.288- 293

- Osunkunle, O. (2008). Campus based radio stations as agents of social change in post-apartheid 1-19.

- Qebral, N. (1988). Development Communication. Philippines: Los Banos.

- Yourhee Jeong, Daeho Kim, Hyun Young Oh, and Yong Chon Park.(2013). Print Media Coverage of Post-Traumatic Stress Disorder: Content Analysis of Three Major Korean Newspapers: J Korean Med Sci 2013; 28: 1077-1082 